\title{
An Estimation of the Efficiency and Satisfaction for EEG Practice Using the Training 10-20 Electrode System: A Questionnaire Survey
}

\author{
Chang Hee Lee ${ }^{1,3, \dagger}$, Dae Jin Kim ${ }^{2,3, \dagger}$, Jeong Su Choi ${ }^{3}$, Jong-Woo Lee ${ }^{4,5}$, Min Woo Lee ${ }^{3}$, Jae Wook \\ $\mathrm{Cho}^{2}$, Suhng Wook Kim ${ }^{3}$ \\ ${ }^{1}$ Department of Neurology, Seoul National University Hospital, Seoul, Korea \\ ${ }^{2}$ Department of Neurology, Pusan National University Yangsan Hospital, Yangsan, Korea \\ ${ }^{3}$ Department of Integrated Biomedical and Life Sciences, Graduate School, Korea University, Seoul, Korea \\ ${ }^{4}$ Department of Neurology, Korea University Ansan Hospital, Ansan, Korea \\ ${ }^{5}$ Department of Laboratory Medicine, Graduate School of Medicine, Kangwon National University, Chuncheon, Korea
}

\section{연습용 10-20 Electrode System을 이용한 뇌파검사 실습의 효율성과 만족도 평가}

\author{
이창희 ${ }^{1,3, \dagger}$, 김대진 $^{2,3, \dagger}$, 최정수 $^{3}$, 이종우 $^{4,5}$, 이민우 $^{3}$, 조재욱 $^{2}$, 김성욱 $^{3}$ \\ ${ }^{1}$ 서울대학교병원 신경과, ${ }^{2}$ 부산대학교 양산병원 신경과, ${ }^{3}$ 고려대학교 대학원 의생명융합과학과, ${ }^{4}$ 고려대학교 안산병원 신경과, ${ }^{5}$ 강원대학교 의학과대학원 \\ 진단검사의학전공
}

\begin{abstract}
Electroencephalography (EEG) is distinct from other medical imaging tests in that it is a functional test that helps to diagnosis disorders related to the brain, such as epilepsy. The most important abilities for a medical technologist when performing an EEG are knowing the exact location of the electrode and recording the EEG wave clearly, except for artifacts. Although theoretical education and practical training are both included in the curriculum for improving these abilities, sufficient practical training has been lacking due to problems like expensive equipment and insufficient practical training time. We try to solve these issues by manufacturing the training 10-20 electrode system and by estimating the efficiency and satisfaction of the training 10-20 electrode system through a questionnaire. The time required for practical training using this system was 43.58 $\pm 9.647 \mathrm{~min}$, which proved to be efficient. The satisfaction score of participants who experienced curriculum practical training was improved from $7.21 \pm 2.285$ to $9.46 \pm 1.166$. Based on these findings, it is considered that practical training via the use of the training 10-20 electrode system will solve the problems, such as lack of equipment and insufficient practical training time. Nonetheless, to further improve the training 10-20 electrode system, it must overcome the limitations of developing a device capable of checking the actual brain waves and validating the exact location of electrode attachment.
\end{abstract}

Key words: Electroencephalography, International 10-20 Electrode system, Training, Medical Technologist

This is an Open Access article distributed under the terms of the Creative Commons Attribution Non-Commercial License (http://creativecommons.org/licenses/by-nc/4.0) which permits unrestricted non-commercial use, distribution, and reproduction in any medium, provided the original work is properly cited.

Copyright ( 2017 The Korean Society for Clinical Laboratory Science. All rights reserved.
${ }^{\dagger}$ The first two authors contributed equally to this work (The patent holders mentioned in Figure 1 are Chang Hee Lee and Dae Jin Kim. They equally contributed to this work, so we request them to be the first $\mathrm{co}^{-}$-authors).

Corresponding author: Suhng Wook Kim Department of Integrated Biomedical and Life Sciences, Graduate School, Korea University, 145 Anam-ro, Seongbuk-gu, Seoul 02841, Korea

Tel: 82-2-3290-5686

Fax: 82-2-940-2829

E-mail: swkimkorea@korea.ac.kr

Received: July 28, 2017 Revised 1 ${ }^{\text {st. }}$ : August 9, 2017

Revised 2 ${ }^{\text {nd }}$ : August 21, 2017 Revised 3 ${ }^{\text {rd: }}$ : August 22, 2017 Accepted: August 22, 2017 


\section{서 론}

뇌 검사중 하나로 알려진 뇌파검사는 컴퓨터 단층촬영(computerized tomography, CT), 자기공명 영상법(magnetic resonance imaging, MRI), 단일광자 단층촬영(single photon emission computed tomography, SPECT)과 같은 해부학적 인 영상검사와는 다르게, 대뇌겉질의 신경 세포군에서 발생한 전기적인 활동을 이용하여 뇌의 기능을 측정하는 전기생리학적 인 검사이다[1]. 뇌파검사는 대표적으로 뇌전증을 진단할 때 임 상적인 증상과 더불어 결정인자로 작용하고[2] 뇌 영역 중 발작 의 시작부위를 결정하는 데 중요한 역할을 하며[3,4] 항경련제 의 선택에 대한 영향을 가진다 [5,6]. 또한 뇌 신경계를 침범하는 감염인 뇌염, 뇌의 진행성 장애인 뇌종양, 뇌혈관 질환인 뇌졸 증, 두부 외상, 치매 등 뇌 질환[7-9]과 다양한 원인에 의한 의식 장애의 유무나 정도, 대사성 혼수, 정신과 질환, 뇌사 판정 등에 서 사용되고 있다[10,11].

뇌파검사는 비침습적으로 두피에 부착한 전극에 대뇌겉질의 미세한 전기적인 활동을 받아들여 뇌파 장비를 통해서 증폭시 키고 기록하게 되는 것이다. 이때 가장 중요한 부분은 전극을 두 피의 어떤 위치에 부착하는지에 대한 것인데, 1958년부터 지난 수십 년 동안 International 10-20 Electrode system을 따라 정해진 위치에 전극을 부착하고 있다[12]. 이후 좀 더 세분화되 고 많은 정보의 뇌파를 관찰하기 위해 10-10 Electrode system 에 따른 부착위치를 사용하기도 한다[13,14]. 이러한 뇌파검사 를 시행하는 임상병리사의 역할은 International 10-20 Electrode system의 정확한 위치에 올바른 방법을 통하여 전극을 부착하고, 인공산물을 제외한 뇌파 파형을 기록하게 하여 판독 을 효율적으로 할 수 있게 하는 것이다. 하지만 임상병리사 업무 의 상당부분을 차지하는 검체 검사와는 달리 인체를 대상으로 하는 검사에서는 대학(교)의 임상병리(학)과를 졸업하고 면허 증을 취득한 신규 임상병리사들에게는 기술적인 측면이 부족하 기 때문에 임상검사를 스스로 진행하기 위해서는 교육기간이 상당히 필요한 부분이 있다. 특히 뇌파검사실에서는 International 10-20 Electrode system에 맞춰 전극을 부착하려면 경험적으로 볼 때 최소 1 개월 이상의 수련기간이 필요한 것으로 사료된다.

또한 대학(교)의 임상병리(학)과 교과과정 중에는 임상생리 학 과목이 있다. 이 과목은 신경계, 순환계, 호흡계, 기타 등으로 구분할 수 있는데 신경계의 한 부분인 뇌파검사학의 교육과정 은 다른 과목들과 마찬가지로 이론적인 부분만 아니라 실습도 포함되어 있다. 그러나 현실적인 교육과정에서 이론적으로 치
중된 부분이 많고 뇌파검사 실습은 고가의 장비와 실습시간 부 족으로 인하여 임상병리사로서의 중요한 역할인 전극 부착방법 에 대해서는 교육이 미흡한 실정으로 생각된다.

본 연구에서는 부족한 실습시간에 효율적으로 교육할 수 있 는 방법을 고민하여 ‘연습용 10-20 Electrode system' 실습도 구를 제작하였다(Figure 1). 또한 제작된 실습도구의 효율성과 만족도를 확인해보고자 하였으며, 사용에 있어 부족한 점이 무 엇인지 설문을 통해 알아보고자 하였다.

\section{재료 및 방법}

\section{1. 대상}

이번 연구는 2016년 하계 실습 기간부터 동계 실습 기간까지 서울대학교 병원, 고려대학교 안산병원, 부산대학교 양산병원 에 실습중인 전국의 임상병리(학)과 학생을 대상으로 하였다. 실험을 시작하기 전 실험의 목적을 설명하고 학생들에게 동의 를 구한 후 시행하였으며, 동의를 거부한 학생은 없었다.

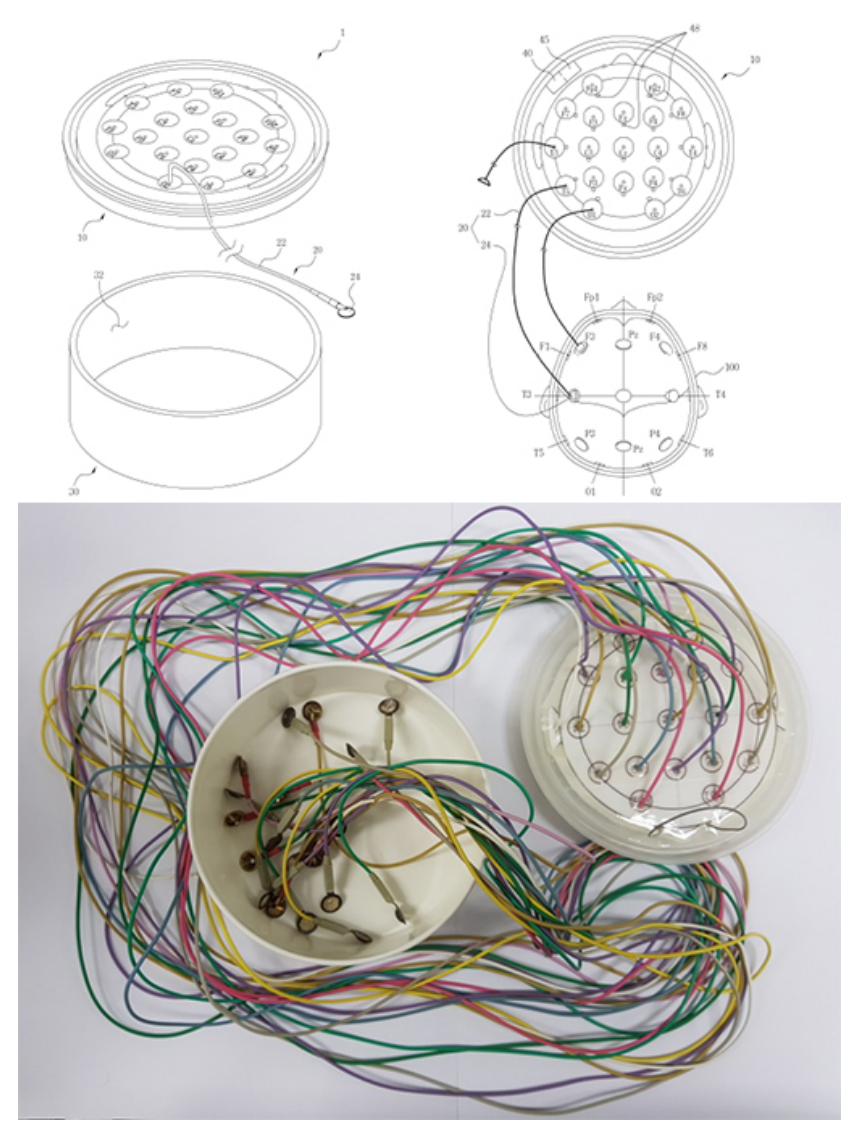

Figure 1. Diagram of training 10-20 electrode system (Application number 10-2014-0024696, Industrial Property Office). 


\section{2. 설문지 작성}

설문에 대한 답변 작성은 연습용 10-20 Electrode system을 사용하여 실험하기 전과 후로 나눠서 2회 실시하였다. 설문 문 항은 본 연구자들이 직접 작성하여 사용하였다.

\section{1) 실습 전 설문지}

교과과정 중 뇌파검사 실습의 유무를 확인하기 위해 “교과과 정 중 임상생리학 실습과목에서 뇌파검사 실습을 해보신 적이 있습니까?”란 문항이 있으며, 위의 질문을 통해서 교과 과정 중 실습을 경험한 학생(유경험자)들에게는 '만족도'(1-10점으로 주관적 표기), '실습 진행방법'(경험적으로 교육과정에서 가능 한 방법 5 문항 중 한 가지 선택, 없으면 추가적으로 기술), '실습 에 대한 애로사항' (경험적으로 예상할 수 있는 애로사항 5 문항 중 복수선택, 없으면 추가적으로 기술)에 대한 문항이 있다. 또 한 교과과정 중 실습을 경험하지 못한 학생(무경험자)들에게는 '실습 미경험의 원인'(경험적으로 예상할 수 있는 원인 4문항 중 한 가지 선택, 없으면 추가적으로 기술)에 대한 문항이 있다.

\section{2) 실습 후 설문지}

연습용 10-20 Electrode system을 사용해서 실습한 만족도 를 확인하기 위해 "연습용 10-20 Electrode system을 사용한 뇌파검사 실습의 만족도는 몇 점입니까?"(1-10점으로 주관적 표기)란 문항이 있으며, 연습용 10-20 Electrode system을 사 용한 실습에 대한 '애로사항' (경험적으로 예상할 수 있는 애로 사항 5문항 중 복수선택, 없으면 추가적으로 기술), '개선사항' (경험적으로 예상할 수 있는 개선사항 4문항 중 복수선택, 없으 면 추가적 기술)에 대한 문항이 있다. 마지막으로 유경험자들에 게 교과과정 중 뇌파검사 실습과 연습용 10-20 Electrode system을 사용한 뇌파검사 실습 중 '두 방법 간 만족도 차이'(2 가지 중 선택, 선택한 이유 기술)에 대한 문항이 있다.

\section{3. 연습용 10-20 Electrode system}

1) International 10-20 Electrode system의 설명

실습 전 설문지를 작성한 학생들을 대상으로 실험의 원활한 진행을 위해 대학(교)에서 뇌파검사학에 대한 강의경력이 있고 5년 이상 뇌파검사에 경험이 있는 숙련된 임상병리사가 International 10-20 Electrode system에 대해 설명을 하였다[12]. 특히 전극을 부착하는 위치를 찾는 법과 전극풀을 사용하여 두 피에 전극을 부착하는 법은 신경기능 검사학(고려의학)에 제시 된 방법으로 하였다[15].

\section{2) 연습용 10-20 Electrode system을 사용한 실험}

2인 1개 조로 편성하여 실험을 진행하고 실습 소요시간 확인 을 위해 타이머를 이용하였다. 전극 부착 위치는 International 10-20 Electrode system을 기준으로 하였으며, 제일 먼저 앞, 뒤로 코뿌리 점과 뒤통수 점을 잇는 선의 중앙 점과 옆으로는 양 쪽 귓바퀴의 앞부분을 잇는 중앙 점의 교차점을 $\mathrm{Cz}$ (기준점) 위 치로 하였다. 머리를 위에서 보며 $\mathrm{Cz}$ 부터 각 코뿌리 점 $(\mathrm{Cz}, \mathrm{Fz}$, $\mathrm{Fpz}$, 뒤통수 점 $(\mathrm{Cz}, \mathrm{Pz}, \mathrm{Oz})$ 왼쪽 귓바퀴의 앞부분 $(\mathrm{Cz}, \mathrm{C} 3, \mathrm{~T} 7)$, 오른쪽 귓바퀴의 앞부분(Cz, C4, T8)까지 $20,20,10 \%$ 되는 지 점, 양쪽 머리 옆에서 보며 $\mathrm{T} 7$ / T8부터 각 $\mathrm{Fpz}$ (T7, F7, Fp1 / T8, F8, Fp2), Oz (T7, P7, O1 / T8, P8, O2)까지 20, 20, 10\% 되는 지점을 표시하였다. 그리고각 F7 / F8과 Fz의 중간 점과각 $\mathrm{Fp} 1$ / Fp2와 $\mathrm{C} 3$ / C4의 중간 점이 교차하는 지점을 $\mathrm{F} 3$ / F4, 각 $\mathrm{P} 7 / \mathrm{P} 8$ 과 $\mathrm{Pz}$ 의 중간 점과 각 $\mathrm{O} 1 / \mathrm{O} 2$ 와 $\mathrm{C} 3$ / C4의 중간 점이 교차하는 지점을 $\mathrm{P} 3 / \mathrm{P} 4$ 지점으로 표시하였다. 전극은 표시해 둔 지점과 $\mathrm{Fpz}$ 와 $\mathrm{Oz}$ 는 제외하고 참고 점인 $\mathrm{A} 1, \mathrm{~A} 2$ 를 추가하여 총 21개를 부착하였다.

\section{4. 통계 처리}

SPSS version 12. 0 통계 프로그램(SPSS Inc., Chicago, IL, $\mathrm{USA})$ 을 사용하여 성별, 학제, 교과과정 중 뇌파검사 실습의 유 무에 따른 인원수를 비교할 때는 Chi-squre test를, 성별, 학제, 교과과정 중 뇌파검사 실습의 유무에 따른 연습용 10-20 Electrode system을 사용한 실습 만족도와, 소요시간 차이를 비교할 때는 Independent $t$-test를, 그리고 유경험자들의 교과 과정 중 실습 만족도와 연습용 10-20 Electrode system을 사용 한 실습 만족도 간의 차이를 비교할 때는 Paired $t$-test를 통해 유의확률 $p<0.05$ 수준으로 통계적 유의성을 확인하였다.

\section{결 과}

\section{1. 대상자 분석}

연구 대상자는 전체 90 명이 모집되었고 남자는 41명

Table 1. General characteristics of study participants ( $N=90)$

\begin{tabular}{llllc}
\hline Characteristics & Classifications & $N(\%)$ & $\chi^{2} .050$ & $\chi^{2}(p)$ \\
\hline Gender & Male & $41(45.6)$ & 3.841 & $0.711(0.399)$ \\
& Female & $49(54.4)$ & & \\
School system & College & $43(47.8)$ & 3.841 & $0.178(0.673)$ \\
& University & $47(52.2)$ & & \\
Practical training & Experienced & $39(43.3)$ & 3.841 & $1.600(0.206)$ \\
& Inexperienced & $51(56.7)$ & & \\
\hline
\end{tabular}


(45.6\%), 여자는 49명(54.4\%)이었다. 3년제는 43명(47.8\%), 4 년제는 47 명(52.2\%)이었고, 교과과정 중 뇌파검사 실습을 경험 한 유경험자는 39명(43.3\%), 교과과정 중 뇌파검사 실습을 경 험하지 않은 무경험자는 51명(56.7\%)으로 나타났다(Table 1).

\section{2. 교과과정 중 뇌파검사 실습}

1) 실습방법(교과과정 중 뇌파검사 실습을 경험한 유경험자 39명을 대상으로 실시)

개인별로 전극을 부착하지 않고 위치만 확인한 학생이 19명 (48.7\%)으로 가장 많았고, 실습으로 인한 실질적 학습 증대 효 과를 기대할 수 있는 최대 인원이 10 명으로 생각되어 조별 실습 인원을 10 명으로 나누어 조사하였는데, 10 명 이하의 조별로 전 극을 붙여본 학생이 16 명(41\%)으로 응답했다. 또한 10 명 이상 의 조별로 전극을 붙여본 학생이 1 명(2.6\%), 반별로 전극을 붙 여본 학생이 3 명 $(7.7 \%)$ 응답했다. 학교 교수님이 시연만 한 곳 은 없었다(Figure 2).

2) 실습 애로사항(교과과정 중 뇌파검사 실습을 경험한 유경 험자 39명을 대상으로 실시)

전극 부착위치를 찾기 어렵다고 답한 학생이 15명(38.4\%)으

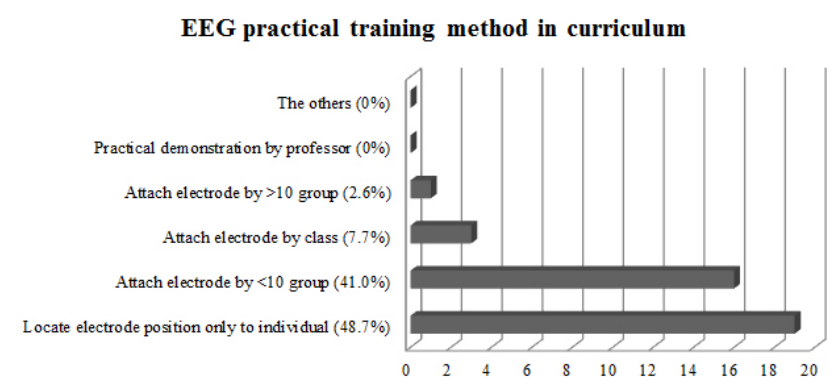

Figure 2. Analysis of survey responses on EEG practical training methods in curriculum against curriculum training experienced students.

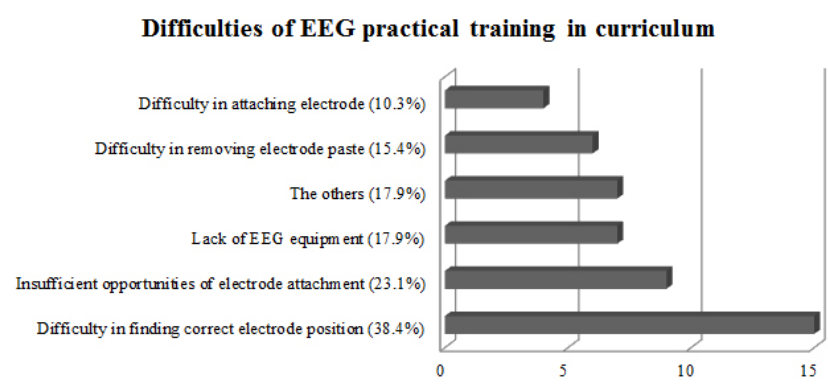

Figure 3. Analysis of survey responses on difficulties of EEG practical training in curriculum against curriculum training experienced students.
로 가장 많았고, 전극 부착 기회가 적어서 아쉬운 학생이 9명 (23.1\%), 장비 부족으로 인한 실습의 효율성이 아쉬운 학생이 7 명(17.9\%) 응답했다. 기타는 7명(17.9\%)이 응답했으며 '실습시 간 부족', '전극 부착위치만 확인' 등의 내용이 있었다. 이 밖에 '전극을 붙이는 것이 어려움' ' '실습 후 전극(풀) 제거 어려움' 등 의 응답이 있었다(Figure 3).

3) 실습 미경험의 원인(교과과정 중 뇌파검사 실습을 경험하지 않은 무경험자 51명을 대상으로 실시)

뇌파 장비가 학교에 구비되지 않은 학생이 26명(51.0\%)으로 가장 많았고, 잘 모른다고 답한 학생이 15명(29.4\%) 응답했다. 또한 학교 교수님이 시연만 진행한 학생이 5 명 $(9.8 \%)$, 병원 실습 후 교과과정에 포함된 학생이 5명(9.8\%) 응답했다(Figure 4).

\section{3. 연습용 10-20 Electrode system을 사용한 뇌파검사 실습}

1) 실습 소요시간 분석(전체 90 명을 대상으로 실시)

전극 부착위치를 표시하는 순간부터 총 21개의 전극을 두피 에 부착하는 순간까지 타이머를 이용하여 실습 소요시간의 평 균과 표준편차는 $43.58 \pm 9.647$ 분으로 측정되었다. 유경험자 의 연습용 10-20 Electrode system을 사용한 뇌파검사 실습 소 요시간은 $43.23 \pm 8.791$ 분, 무경험자의 실습 소요시간은 $43.84 \pm 10.331$ 분으로 측정되었다. 남자의 연습용 10-20 Electrode system을 사용한 뇌파검사 실습 소요시간은 $43.49 \pm 9.887$ 분, 여자의 실습 소요시간은 $43.65 \pm 9.543$ 분으 로 측정되었고, 3년제 학생의 연습용 10-20 Electrode system

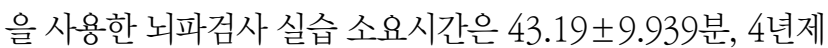
학생의 실습 소요시간은 $43.94 \pm 9.465$ 분으로 측정되었다 (Table 2).

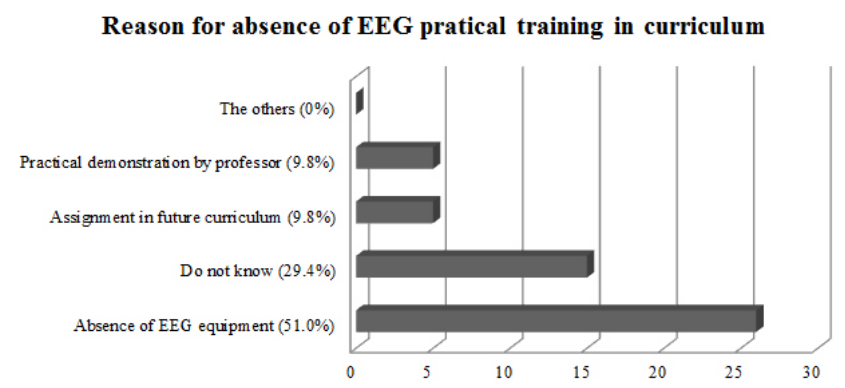

Figure 4. Analysis of survey responses on reason for absence of EEG practical training in curriculum against curriculum training inexperienced students. 
Table 2. The time required and satisfaction score of training 10-20 according to general characteristics

\begin{tabular}{|c|c|c|c|c|c|}
\hline \multirow{2}{*}{ Characteristics } & \multirow{2}{*}{ Classifications } & \multicolumn{2}{|c|}{ Time (min) } & \multicolumn{2}{|c|}{ Score $($ range=1 $\sim 10)$} \\
\hline & & $\mathrm{M} \pm \mathrm{SD}$ & $\mathrm{t}(p)$ & $M \pm S D$ & $\mathrm{t}(p)$ \\
\hline Total $(\mathrm{N}=90)$ & & $43.58 \pm 9.647$ & & $9.57 \pm 0.887$ & \\
\hline \multirow[t]{2}{*}{ Gender } & Female $(\mathrm{N}=49)$ & $43.65 \pm 9.543$ & $0.080^{\dagger}(0.936)$ & $9.43 \pm 1.099$ & $-1.714^{\dagger}(0.091)$ \\
\hline & Male $(\mathrm{N}=41)$ & $43.49 \pm 9.887$ & & $9.73 \pm 0.500$ & \\
\hline \multirow[t]{2}{*}{ School system } & College $(N=43)$ & $43.19 \pm 9.939$ & $-0.367^{\dagger}(0.715)$ & $9.51 \pm 1.077$ & $-0.550^{\dagger}(0.584)$ \\
\hline & University $(\mathrm{N}=47)$ & $43.94 \pm 9.465$ & & $9.61 \pm 0.099$ & \\
\hline \multirow[t]{2}{*}{ Practical training } & Inexperienced $(\mathrm{N}=51)$ & $43.84 \pm 10.331$ & $0.297^{\dagger}(0.767)$ & $9.65 \pm 0.593$ & $0.898^{\dagger}(0.373)$ \\
\hline & Experienced $(\mathrm{N}=39)$ & $43.23 \pm 8.791$ & & $\begin{array}{l}9.46 \pm 1.166 \\
7.21 \pm 2.285^{\S}\end{array}$ & $6.521^{\ddagger}(0.000)^{\star \star *}$ \\
\hline
\end{tabular}

${ }^{\dagger}$ t-test statistic was calculated by independent two-sample t-test. ${ }^{\dagger}$ t-test statistic was calculated by paired t-test. ${ }^{\S}$ Satisfaction score of electroencephalography practical training included in curriculum. ${ }^{* \star} p<0.001$.

A

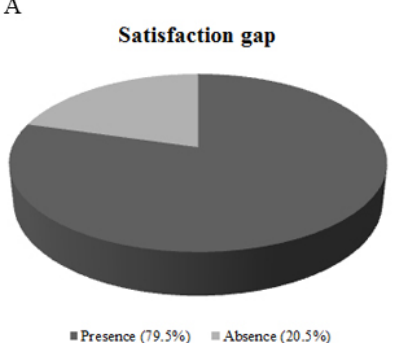

B

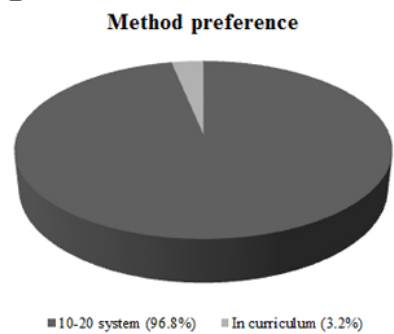

Figure 5. (A) Analysis of survey responses on satisfaction gap against curriculum training experienced students. (B) Analysis of survey responses on method preference against curriculum training experienced students.

\section{2) 실습 만족도 분석(전체 90 명을 대상으로 실시)}

전체 학생의 연습용 10-20 Electrode system을 사용한 뇌파 검사 실습을 경험한 만족도 평균 및 표준편차는 $9.57 \pm 0.887$ 점 으로 나타났다. 세부적으로 비교해보면 유경험자의 교과과정 중 뇌파검사 실습의 만족도는 7.21 \pm 2.285 점, 연습용 10-20 Electrode system을 사용한 뇌파검사 실습의 만족도는 $9.46 \pm$ 1.166점으로 만족도의 차이를 보였다. 무경험자의 연습용 10-20 Electrode system을 사용한 뇌파검사 실습의 만족도는 $9.65 \pm 0.593$ 점으로 나왔다. 남자의 연습용 10-20 Electrode system을 사용한 뇌파검사 실습의 만족도는 $9.73 \pm 0.500$ 점, 여자의 만족도는 $9.43 \pm 1.099$ 점으로 나타났고, 3년제 학생의 연습용 10-20 Electrode system을 사용한 뇌파검사 실습의 만

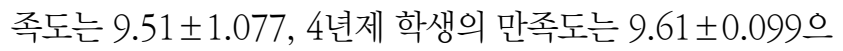
로 나왔다(Table 2).

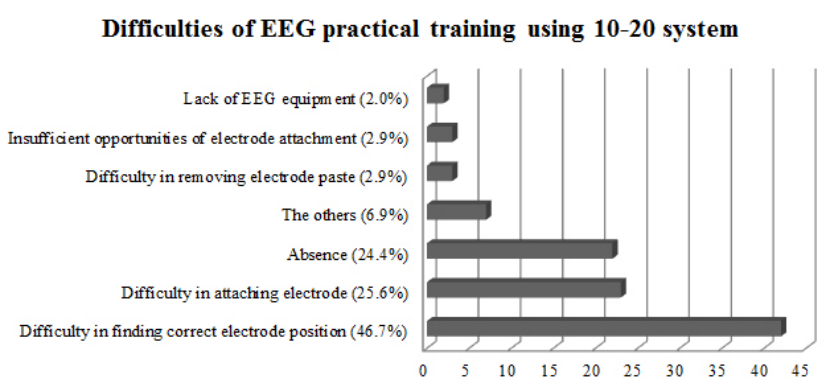

Figure 6. Analysis of survey responses on difficulties of EEG practical training using training 10-20 electrode system against all participants.

3) 교과과정 중 뇌파검사 실습과 연습용 10-20 Electrode system을 사용한 뇌파검사 실습 간 만족도 비교(유경험 자 39명을 대상으로 실시)

두 종류의 실습방법이 만족도의 차이가 있다고 응답한 학생 은 31명(79.5\%)이었고, 차이가 없다고 응답한 학생은 8명 (20.5\%)으로 나타났다. 차이가 있다고 응답한 학생들 중 연습용 10-20 Electrode system을 사용한 실습방법이 30명(96.8\%), 교과과정 중 실습방법은 1명(3.2\%)이 만족도가 더 높다고 대답 했다. 연습용 10-20 Electrode system을 사용한 뇌파검사 실습 의 만족도가 높은 이유로는 ‘뇌파검사실 선생님의 피드백' ‘사 람을 대상으로 실제로 전극풀을 사용' , '혼자서 전극을 전부 붙 여볼 수 있음' '병원 실무에 가까운 실습' , '실제 뇌파 장비보다 간단하고 실용성이 높다'는 등의 내용이 있었다(Figure 5).

4) 실습 애로사항 및 개선사항(전체 90명을 대상으로 실시) 전극 부착위치를 찾기 어렵다고 답한 학생이 42 명(46.7\%)으 로 가장 많았고, 전극(풀)을 붙이는 것이 어렵다고 답한 학생이 23 명(25.6\%), 애로사항이 없다고 대답한 학생이 22명(24.4\%) 응답했다. 그 밖의 응답으로는 '실습 후 전극풀 제거 어려움', 


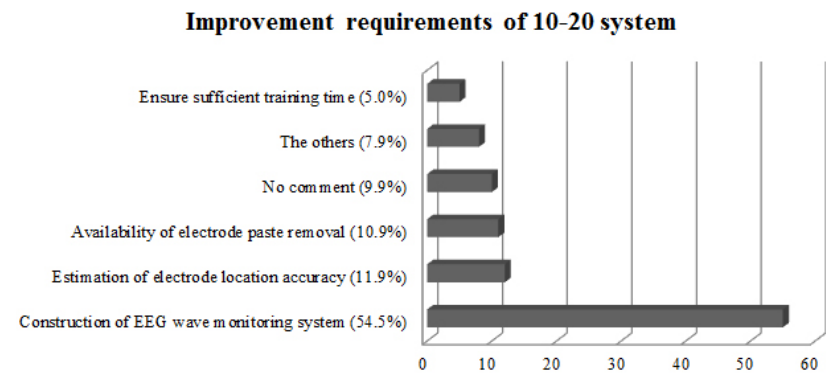

Figure 7. Analysis of survey responses on improvement requirements of training 10-20 electrode system against all participants.

'실험도구의 부족으로 인한 효율성 저하' '전극 부착 기회가 적 음' 등이 있었으며, 기타 의견으로는 '긴 머리 학생을 대상으로 실습하기 어려움', '실험 후 정확한 위치를 확인하는 피드백의 부족' 등이 있었다(Figure 6).

또한 개선사항으로는 전극 부착 후 실제 뇌파를 확인하고 싶 은 학생이 55명(61.1\%)으로 가장 많았고, 애로사항과 마찬가지 로 '전극 부착 위치의 정확도 확인', '전극풀을 쉽게 제거하기', '충분한 실습시간 필요함' 등이 있었으며 기타 의견으로는 '사 람보다 마네킹을 대상으로 실습을 진행하면 좀 더 편한 실습일 거 같다'는 의견이 있었다(Figure 7).

\section{고 찰}

전국의 임상병리(학)과에는 임상병리사로서의 기본 자질을 갖추기 위해 임상화학, 임상미생물학, 임상혈액학, 조직병리학, 임상생리학 등 다양한 학문이 교과과정에 포함되어 있다[16]. 임상병리사의 업무가 이론적인 지식도 중요하지만 검체검사나 생체검사를 주로 하기 때문에 기술적인 측면이 더 필요하다. 더 욱이 보편화된 간편하고 자동화되고 있는 검체검사는 업무의 기술 의존도가 감소되고 있지만, 임상생리학 분야는 개선된 검 사 장비는 많이 사용되고 있으나 여전히 임상병리사의 기술력 에 의존하고 있다. 그래서 여전히 교과과정 중에는 이론과 실습 을 병행하는 것이 필요한 이유이다. 이러한 실습을 통한 상당 수 준의 기술 습득이 임상병리사 뿐만 아니라 집도의를 준비하는 의대생들에게도 중요한 요건으로 연구되었다[17]. 그러나 대부 분의 임상생리학 실습 중 비교적 저렴한 가격의 심전도와 폐기 능 검사장비는 구비되어 있으나 나머지 검사장비는 고가의 가격 으로 인해 학교 내에 구비되지 못하고 있는 실정이다. 특히 신경 계 검사장비는 숙련된 기술력의 필요성과장비 운영의 어려움으 로 구비되어 있는 곳이 많지 않고, 구비되어 있어도 원활한 운영 이 쉽지 않기 때문에 교과과정 중 실습은 제한된 부분이 많다.
또한 임상생리학 검사의 임상병리사의 업무는 기록된 자료를 확인하며 판독하는 것이 아닌 인체에서 발생하는 신호를 정확하 게 기록하는 것에 있다. 뇌파검사는 명확한 기록을 위해서 무엇 보다 정확한 전극 부착위치의 숙지 및 숙련된 전극 부착, 인공산 물을 제거할 수 있는 능력이 요구된다. 특히 전극 부착 위치는 상 당히 중요한 부분이기에 International 10-20 Electrode system에 부합해 정확한 전극 부착위치를 찾는 연구도 있다[18].

본 연구에서 확인한 결과, 무경험자 중 뇌파검사장비 부재를 미경험의 원인으로 인지하고 있는 학생이 26 명(51.0\%)으로 가 장 높은 순위로 조사되어 장비 부재로 인한 실질적이고 체계적 실습 상실이 일어나고 있는 것으로 사료되고, 학교 교수의 시연 만 진행한 학생도 5명(9.8\%)으로 조사된 것으로 보아 이 또한 장 비 부족으로 인한 실습시간의 효율적 운영을 위해 부득이하게 실시된 부적절한 실습으로 추측된다. 유경험자가 응답한 실습 진행 방법을 보더라도 전극을 부착하지 않고 부착위치만 확인 한 학생이 19명(48.7\%)으로 가장 높은 순위로 장비 부족으로 인 해 실질적인 실습이 어려운 것으로 볼 수 있다. 최소한의 실질적 학습 증대 효과를 기대할 수 있는 10명 이하의 조 편성으로 실시 했다는 학생이 16명(41.0\%)으로 두 번째로 높은 응답률을 보였 으나장비 부족으로 인해 좀 더 원활하고 숙련도를 높이기 위한 실습으로는 한계가 있는 것으로 사료된다. 또한 간호(학)과 학 생들을 대상으로 한 조사 결과, 학생들이 이론 수업의 이해력을 높이기 위한 시신해부실습의 필요성을 체감하고 있다는 연구 결과[19] 및 분만간호 핵심술기에 대한 시뮬레이션 실습교육을 실시한 후 자신감 향상되었다는 결과를[20] 통해 실질적, 효율 적, 체계적 실습에 대한 학생들의 요구가 큰 것을 알 수 있다. 본 연구에서 유경험자의 애로사항 중에서 '전극의 부착위치를 찾 는 어려움' 15 명(38.4\%), '전극(풀) 부착 기회의 부족' 9명 (23.1), '장비 부족으로 인한 실습의 효율성 저하' 7명(17.9\%) 등 대다수의 학생이 장비 부족과 이로 인한 실습시간 부족과 관 련된 문제를 애로사항으로 응답하고 있어 위와 같은 학생들의 요구를 충족시키는데 있어서 현재의 교과 과정 중 실습은 한계 가 있는 것으로 생각된다.

위에 언급된 내용을 종합해보면, 교과과정 중 뇌파검사 실습 에 대한 문제점은 장비의 고가로 인한 장비 부재 및 부족이 실습 시간의 부족으로 연결된다는 점이고 이를 해결하기 위해 제작 한 연습용 10-20 Electrode system을 사용하여 실습하면서 효 율성과 만족도, 애로사항과 개선사항을 확인하였다. 먼저 연습 용 10-20 Electrode system을 사용한 뇌파검사 실습의 효율성 은 실습 소요시간을 통해서 분석한 결과, 전체 학생들의 실습 소 요시간은 $43.58 \pm 9.647$ 분으로 측정되어 교과과정 중 실습시 
간 동안 반복 실습이 가능할 것으로 사료되어 효율성이 입증된 것으로 판단하였다. 또한 남자-여자, 3년제-4년제, 유경험자무경험자로 그룹을 나누어 비교 대조하였을 때 그룹 간의 차이 가 거의 없는 것으로 보아 연습용 10-20 Electrode system을 사용한 뇌파검사 실습은 평균적으로 동일한 난이도를 가지는 것으로 추측된다. 만족도 측면에서는 전체 90 명의 만족도가 $9.57 \pm 0.887$ 점으로 높은 만족도를 보였다. 특히 유경험자의 교 과과정 뇌파검사 실습 만족도가 $7.21 \pm 2.285$ 점인데 비해 연습 용 10-20 Electrode system을 사용했을 때의 실습 만족도가 $9.46 \pm 1.166$ 점으로 $31.9 \%$ 상당 수준 향상되었고 무경험자 역 시 9.65 \pm 0.593 점으로 비슷한 수준의 만족도를 나타냈다. 또한 남자-여자, 3년제-4년제 등 그룹 간 비교 대조에서도 유의한 만 족도의 차이 없는 것으로 보아 어떤 대상에서도 높은 만족도를 보여 연습용 10-20 Electrode system가 생소한 학문인 뇌파검 사학을 좀 더 흥미롭게 접근할 수 있는 좋은 기회를 제공하고 있 는 것으로 나타났다. 더욱이 교과과정 실습과 연습용 10-20 Electrode system 간 만족도 비교에서 유경험자 39명 중 31명 (79.5\%)이 차이가 있다고 응답했고, 이중 30명(96.8\%)은 연습 용 10-20 Electrode system을 사용한 뇌파검사 실습의 만족도 가 더 높은 것으로 선택한 것으로 보아, 대부분의 학생이 스스로 인지할 만큼의 만족도의 차이가 있고 연습용 10-20 Electrode system을 사용한 실습이 현재의 교과과정 실습보다 실질적, 효 율적, 체계적 실습에 가까운 것으로 추측된다.

연습용 10-20 Electrode system의 애로사항을 보면 유경험 자가 교과과정 중 뇌파검사 실습에서의 애로사항에서 가장 많 이 응답한 전극 부착위치를 찾기 어렵다는 내용이 이번에도 마 찬가지로 42명(46.7\%)으로 가장 높은 순위였다. 그러나 정확한 전극 부착위치를 찾는 것을 숙련되게 하기 위해선 경험적으로 볼 때 1 개월 이상 소요될 것이라고 생각되어 한 번의 실습으로 는 해결이 불가능할 것이다. 또한 전극(풀)을 붙이는 것의 어려 움을 답한 학생이 23 명(25.6\%)으로 이것 역시 숙련도의 부족이 라고 판단된다. 이러한 숙련도 부족은 철저한 이론교육과 그에 맞는 실습이 병행될 때 좀더 쉽게 해결할 수 있는데 혈액투석 교 육 프로그램을 개발하여 자기만족도와 수행능력이 유의하게 증 가였다는 연구 결과와[21] 마찬가지로 연습용 10-20 Electrode system을 사용한 반복적 실습을 통해 해결할 수 있을 것이다.

그러나 연습용 10-20 Electrode system을 사용한 실습 학생 들 중 55명(61.1\%)이 실제 뇌파 확인이 불가능한 점을 개선할 문제점으로 제시하였고, 그 외 '전극 부착위치의 정확도 확인', '전극풀을 쉽게 제거하는 것', '더 많은 실습시간의 필요' 가 개선 사항으로 파악됐다. 이는 현재 제작된 연습용 10-20 Electrode system의 한계라고 생각되며, 본 연구자들은 실제 뇌파의 확인 을 위해 전극이 연결되어 있는 제품의 뚜껑 부분을 실제 뇌파 장 비의 전극 접속 상자에 그려져 있는 전극 부착위치와 동일하게 제작하여 실습 후 바로 연동이 가능한 향상된 제품 개발 및 정확 한 부착위치를 확인할 수 있는 마네킹의 제작 등에 대한 연구가 꾸준히 필요할 것으로 사료된다. 또한 다른 신경계 분야의 연습 용 실습도구도 연구하고 제작하여 고가의 장비로 인해 구입이 어려운 부분들을 해소할 수 있기를 기대한다.

\section{요 약}

뇌파검사는 영상검사와는 달리 기능검사로 간질을 진단하고 뇌와 관련된 질환들의 진단에 도움이 된다. 뇌파검사를 시행하 는 임상병리사의 가장 중요한 점은 정확한 전극 부착 위치를 확 인하여 전극을 부착하고 인공산물을 제외한 순수한 뇌파를 기 록하는 것에 있다. 이를 위하여 교과과정에서 이론적인 부분과 함께 실습을 포함시키고 있다. 그러나 고가의 장비와 실습시간 의 부족 때문에 충분한 실습을 할 수 없는 실정이다. 본 연구에서 는 위에 언급된 사항을 해결하고자 연습용 10-20 Electrode system을 제작하여 설문지를 통해 만족도와 실용성을 확인하 고자 한다. 연습용 10-20 Electrode system을 사용한 실습시간 은 43.58 9 9.647분으로 측정되어 효율성을 확인하였다. 또한 교과과정 중 뇌파검사 실습을 진행한 학생(유경험자)의 만족도 는 7.21 \pm 2.285 점, 연습용 10-20 Electrode system을 사용한 실습 만족도는 $9.46 \pm 1.166$ 점으로 상당 부분 향상되었다. 세부 적으로 보면 유경험자는 교과과정 중 실습할 때 전극 부착 위치 만 확인하고, 전극은 단체로 붙여보는 실습을 했고. 애로사항 중 전극 부착위치가 찾기 어려움이 가장 높게 나타났다. 무경험자 는 교과과정 중 뇌파 장비의 부재로 인해 실습을 하지 못했다. 연 습용 10-20 Electrode system을 사용하여 실습했을 때는 전극 부착위치를 찾는 것과 전극(풀)을 부착하는 어려움이 교과과정 중 실습할 때와 마찬가지로 가장 많이 아쉬움으로 나타났다. 위 에 언급된 내용을 보면 연습용 10-20 Electrode system을 사용 하여 실습을 하게 되면 부족한 장비와 실습시간으로 인한 문제 점을 해결 가능할 것이라고 사료된다. 그러나 연습용 10-20 Electrode system의 실제 뇌파 확인, 정확한 부착위치 확인 등 한계점을 개선하여 좀 더 실현성 있는 실습도구가 되도록 연구 가 필요하고 더 나아가 다른 분야도 마찬가지로 고가의 장비로 인해 어려운 부분을 해결할 수 있을 것이라 기대한다. 
Acknowledgements: None

Funding: None

Conflict of interest: None

\section{REFERENCES}

1. Rojas GM, Fuentes JA, Gàlvez M. Mobile device applications for the visualization of functional connectivity networks and EEG electrodes: iBraiN and iBraiNEEG. Can J Neurol Sci. 2016;10 (40):1-6.

2. Pillai J, Sperling MR. Interictal EEG and the diagnosis of epilepsy. Epilepsia. 2006;47(Suppl 1):14-22.

3. Engel J Jr, Wiebe S, French J, Sperling M, Williamson P, Spencer D, et al. Quality Standards Subcommittee of the American Academy of Neurology, American Epilepsy Society, American Association of Neurological Surgeons. Practice parameter: Temporal lobe and localized neocortical resections for epilepsy: Report of the quality standards subcommittee of the american academy of neurology, in association with the american epilepsy society and the american association of neurological surgeons. Neurology. 2003;60(4):538-547.

4. Jan MM, Sadler M, Rahey SR. Electroencephalographic features of temporal lobe epilepsy. Can J Neurol Sci. 2010;37(4):439448.

5. Arzy S, Allali G, Brunet D, Michel CM, Kaplan PW, Seeck M. Antiepileptic drugs modify power of high EEG frequencies and their neural generators. Eur J Neurol. 2010;17(10):1308-1312.

6. Salinsky MC, Oken BS, Storzbach D, Dodrill CB. Assessment of CNS effects of antiepileptic drugs by using quantitative EEG measures. Epilepsia. 2003;44(8):1042-1050.

7. Schmitt SE, Pargeon K, Frechette ES, Hirsch LJ, Dalmau J, Friedman D. Extreme delta brush: A unique EEG pattern in adults with anti-NMDA receptor encephalitis. Neurology. 2012;79(11):1094-1100.

8. Sharanreddy M, Kulkarni P. Automated EEG signal analysis for identification of epilepsy seizures and brain tumour. J Med Eng Technol. 2013;37(8):511-519.

9. Poryazova R, Huber R, Khatami R, Werth E, Brugger P, Barath K, et al. Topographic sleep EEG changes in the acute and chronic stage of hemispheric stroke. J Sleep Res. 2015;24(1):54-65.

10. Soininen H, Partanen J, Laulumaa V, Helkala EL, Laakso M, Riekkinen PJ. Longitudinal EEG spectral analysis in early stage of alzheimer's disease. Electroencephalogr Clin Neurophysiol. 1989;72(4):290-297.

11. Szurhaj W, Lamblin MD, Kaminska A, Sediri H; Société de Neurophysiologie Clinique de Langue Française. EEG guidelines in the diagnosis of brain death. Neurophysiol Clin. 2015;45(1): 97-104.

12. Jasper HH. The ten twenty electrode system of the international federation. Electroencephalogr Clin Neurophysiol. 1958;10: 371-375.

13. Electrode Position Nomenclature Committee. Guideline thirteen: Guidelines for standard electrode position nomenclature. J Clin Neurophysiol. 1994;11(1):111-113.

14. Nuwer MR, Comi G, Emerson R, Fuglsang-Frederiksen A, Guérit J, Hinrichs H, et al. IFCN standards for digital recording of clinical EEG. Electroencephalogr Clin Neurophysiol. 1998; 106(3): 259-61.

15. Kang JH, Yoon JS, et al. Clinical neurophysiology. 1st ed. Seoul: Korea medical book publishing Company; 2017. p59-70.

16. Whang SC, Park EB, Song JO. Revision of the current curriculum for the education of medical technology and the development of model curriculum for the future use. Korean J Clin Lab Sci. 1987;19(1):7-42.

17. Cavalini WLP, Claus CMP, Dimbarre D, Filho AMC, Bonin EA, Loureiro MdP, et al. Development of laparoscopic skills in medical students naive to surgical training. Einstein (Sao Paulo). 2014;12(4):467-472.

18. Cavallaro M. Technical tips: Another way to approach the 10-20 system of electrode placement. Am J EEG Technol. 1992;32(3):225-232.

19. Kim DI. Questionnaire survey analysis on necessity of cadaveric dissection for nursing students: In scope of nursing students and professors. Korean J Phys Anthrop. 2015;28(2):119-125.

20. Song YA, Son YJ. Effects of simulation-based practice education for core skill of maternity nursing. Korean Parent Child Health J. 2013;16(1):37-44.

21. Kim YM, Chun IS, Park YM. Development of a hemodialysis nurse educational program and its effects. J Korea Acad Industr Coop Soc. 2012;13(12):5839-5848. 